\title{
Molecular genetics of oligodendrogliomas: a model for improved clinical management in the field of neurooncology
}

\author{
Catherine L. Nutt, Ph.D. \\ Molecular Neuro-Oncology Laboratory and Molecular Pathology Unit, Departments of Pathology, \\ Neurosurgical Service and Cancer Center, Massachusetts General Hospital and Harvard Medical \\ School, Boston, Massachusetts
}

\begin{abstract}
Over the last several years, oligodendroglial tumors have become a model for the positive role of molecular genetics in improved treatment of patients with brain tumors. Oligodendrogliomas, in contrast to astrocytic gliomas, frequently respond to chemotherapy and have a better overall prognosis. Combined loss of chromosomes $1 \mathrm{p}$ and $19 \mathrm{q}$ has proven to be a powerful predictor of chemotherapeutic response and survival in oligodendrogliomas. In contrast, other genetic alterations, such as TP53 and PTEN mutations, EGFR amplification, and homozygous deletion of CDKN2A have been correlated with worse outcome in these tumors. Furthermore, 1p/19q loss has been shown to correlate with unequivocal oligodendroglial tumor histology, location and growth pattern of tumors within the brain, and magnetic resonance imaging characteristics. Although much is also known about the molecular pathological characteristics of astrocytic gliomas, the significance of this information to clinical management in patients with these tumors has not been as striking as has been the case for oligodendrogliomas; possible reasons for this are discussed. In this paper the author will summarize these advances, thus attempting to highlight the molecular genetic study of oligodendrogliomas as a model for improved clinical management in the field of neurooncology.
\end{abstract}

\section{KEY WORDS • oligodendroglioma - glioma • molecular genetics • chemotherapy • prognosis}

Malignant gliomas are the most common primary brain tumors. These diffusely growing lesions have a distinct ability to invade the surrounding normal tissue, essentially preventing surgical cure. This phenomenon accounts for much of the high mortality rate associated with malignant glial tumors. To complicate matters, many of these tumors are resistant to standard therapeutic approaches. Nevertheless, glial lesions are extremely heterogeneous and some subtypes of diffuse glioma do in fact respond to therapy, thus highlighting the importance of proper classification.

The most widely used method of brain tumor classification is that of the WHO, ${ }^{54}$ which is based on histological examination of the tumor tissue. The diffuse gliomas can be divided into one of three lineages according to histological appearance: astrocytoma, oligodendroglioma, and oligoastrocytoma. Oligodendroglial tumors are classified as such because they are considered to have a cellular morphology most closely resembling that of the normal oligodendrocyte. Briefly, oligodendrogliomas are characterized histologically by cells with round, uniform nuclei and peri-

Abbreviations used in this paper: CCNU = 1-(2-chloroethyl)-3cyclohexyl-1-nitrosourea; $\mathrm{CGH}=$ comparative genomic hybridization; EGFR = epithelial growth factor receptor; MR = magnetic resonance; $\mathrm{PCV}=$ procarbazine, $\mathrm{CCNU}$, and vincristine; $\mathrm{WHO}=$ World Health Organization. nuclear halos (an artifact of standard tissue preparation), and often exhibit delicate, branching vessels as well as calcification. The WHO classification system also assigns a tumor grade to glial lesions. Grade II is the lowest grade given for malignant oligodendroglioma. Grade III (anaplastic) oligodendrogliomas are more densely cellular than Grade II tumors, and are distinguished from Grade II lesions by the observation of brisk mitotic activity. Anaplastic oligodendrogliomas can also exhibit vascular proliferation and/or necrosis. Grade III is the highest grade given to oligodendrogliomas.

In the majority of cases, the WHO classification system can be used successfully to assign tumors to specific, relevant categories. Nevertheless, pathological diagnosis remains quite subjective, ${ }^{64}$ leading to some inadequacies in the current system. For example, intratumoral histological variability can make it difficult to place some gliomas neatly into one of the defined categories. Moreover, high-grade gliomas may exhibit little cellular differentiation, thereby lacking defining histological features. The diagnosis of tumors with such nonclassic histological features can therefore be controversial. Furthermore, tumor grading can be difficult when only tissue from small stereotactic biopsy samples is available for examination. ${ }^{34}$ Consequently, diagnosis of glial tumors can be challenging, and the resulting 
interobserver variability can jeopardize diagnostic accuracy and reproducibility.23,33 Furthermore, even when a histological diagnosis is virtually indisputable, the corresponding predicted clinical behavior does not always concur with the patient's actual clinical course. Moreover, it is unlikely that the current WHO classification system alone will accurately predict patient response to novel targeted molecular therapies as they become available in the future. For these reasons, information capable of refining the WHO system could result in marked improvements in the current approach to brain tumor classification and, subsequently, aid the clinical management of gliomas. To this end, advances in molecular genetics have revolutionized the classification and clinical management of one subtype of malignant glioma, anaplastic oligodendrogliomas. In this paper I will review some of these advances, many of which are summarized in Fig. 1, with the goal of highlighting the promise of this approach as a model for improved clinical management in neurooncology as a whole.

\section{Molecular Genetics of Oligodendroglial Tumors}

The most common genetic alteration in oligodendrogliomas is the combined allelic loss of the short arm of chromosome 1 (1p) and the long arm of chromosome 19 (19q), affecting 50 to $90 \%$ of tumors. ${ }^{7,8,55,85,109}$ These chromosomal losses are detected in Grade II as well as Grade
III lesions, suggesting an early role in oligodendroglial tumorigenesis. The fact that losses of chromosome $1 \mathrm{p}$ and $19 q$ are closely correlated implies that the corresponding putative tumor suppressor genes may be involved in biologically distinct pathways that act synergistically in oligodendroglial tumorigenesis. ${ }^{7,40,55,85}$ Mapping of these chromosome loci has implicated the telomeric region of $1 \mathrm{p}$ and $19 q 13,3,27,30,37,43,55,90,97,100,120$ In the search for potential oligodendroglial tumor suppressor genes within the regions of $1 p$ and $19 q$ loss, examples of commonly mutated genes have not been forthcoming. Therefore, a number of laboratories have begun to focus on possible alternative genetic and epigenetic mechanisms for modulating gene expression, including polymorphisms and methylation., ${ }^{1,25,26,41,105}$, 118,119

Additional genetic alterations found commonly in anaplastic oligodendrogliomas include allelic losses of chromosome 9 involving the $C D K N 2 A$ gene, and chromosome 10.9,10,18,40,46,92,104 Homozygous deletions of CDKN2A on 9 p21 occur in up to one third of anaplastic oligodendrogliomas. ${ }^{40}$ Both $9 \mathrm{p}$ and $10 \mathrm{q}$ aberrations are more common in tumors without $1 \mathrm{p} / 19 \mathrm{q}$ loss. ${ }^{18,40,46}$ Disruption of the cell cycle through the RB1/CDK4/p16 $6^{\mathrm{INK} 4 \mathrm{a}} / \mathrm{p} 15^{\mathrm{INK} 4 \mathrm{~b}}$ and the $\mathrm{p} 53 /$ p14 ${ }^{\mathrm{ARF}} / \mathrm{MDM} 2$ pathways is common in anaplastic oligodendrogliomas, ${ }^{9,115,118}$ with simultaneous disruption of these two pathways suggested to occur in approximately half of

\section{Loss of $1 \mathrm{p} / 19 \mathrm{q}$}

Frontal, parietal and occipital lobes

Bilateral pattern of growth

Diffuse enhancement

Indistinct borders on $\mathrm{Tl}$

Elevated metabolism

\section{Combined, isolated $1 \mathrm{p} / 19 \mathrm{q}$ loss}

Close to $100 \%$ response rate

Response duration greater than 31 months

Survival greater than 10 years

1p loss without $19 \mathrm{q}$ loss
or with other defined genetic alterations
Close to $100 \%$ response rate
Response duration of approximately 11 months
Survival of approximately 6 years

TP53 mutation

Approximately $33 \%$ response rate

Response duration of approximately 7 months

Survival of approximately 6 years

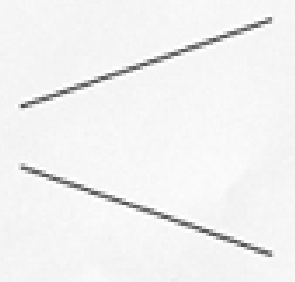

No TP53 mutation, often with other defined genetic alterations Approximately $18 \%$ response rate

Response duration of approximately 5 months Survival of less than $11 / 2$ years

Fig. 1. Flow charts summarizing key clinical features correlated with $1 \mathrm{p}$ loss in oligodendroglial tumors (see text for details). "Other" defined genetic alterations include TP53 mutation, 10q loss, PTEN mutation, EGFR amplification, or deletion of $C D K N 2 A$. T1 = $\mathrm{T}_{1}$-weighted MR imaging. 
the tumors. ${ }^{115}$ In particular, hypermethylation may be an important epigenetic mechanism by which oligodendrogliomas escape such cell cycle control. ${ }^{26,114,115,118}$

Oncogene amplification has rarely been found in oligodendroglial tumors, most commonly affecting EGFR, PDGFRA, and CDK4. $\cdot^{31,84,101}$ A number of other less common chromosomal aberrations have been demonstrated in oligodendrogliomas ${ }^{9,11,24,48,52,56,88,89}$ and, with increasing numbers of high-resolution array-based CGH studies being performed, ${ }^{11,24,52,88,89}$ these data are expected to yield better boundary definition for the discovery of potential novel genes involved in oligodendroglial tumorigenesis. Moreover, gene expression-based microarray and proteomic analyses are also providing massive quantities of molecular genetic data to be mined for insights into tumorigenesis in oligodendroglioma. ${ }^{32,42,47,51,73,75,116}$

\section{Response of Oligodendrogliomas to Chemotherapy and the Predictive Value of Molecular Genetics}

Historically, although diffuse gliomas were classified into diagnostic subgroups, this made little difference in the clinical management of these lesions; all patients with malignant gliomas were treated according to standardized treatment protocols regardless of whether they had an astrocytic or oligodendroglial tumor. This approach began to shift in 1988, when it was first reported that recurrent anaplastic oligodendrogliomas sometimes displayed a marked response to the chemotherapeutic regimen of $\mathrm{PCV} .{ }^{17}$ This was quickly followed up by a report in 1990 confirming that newly diagnosed anaplastic oligodendrogliomas also responded to PCV therapy. ${ }^{67}$ Subsequently, low-grade (WHO Grade II) oligodendrogliomas and oligoastrocytomas were also found to respond favorably to chemotherapy. ${ }^{35,50,58,68}$ Furthermore, oligodendroglial tumors have also been shown to respond to temozolomide,,$^{22,106,107}$ a newer chemotherapy drug that can be taken orally and is often better tolerated by patients.

The most significant example to date of molecular genetics aiding the clinical management of malignant gliomas is the use of $1 p / 19 q$ testing to predict the response of oligodendrogliomas to chemotherapy. Allelic loss of chromosome $1 \mathrm{p}$ in anaplastic oligodendrogliomas has proven to be a powerful predictor of tumor response to PCV treatment. ${ }^{18,46,98}$ Loss of $1 p$ also appears to predict the response of anaplastic oligodendrogliomas to temozolomide as well as that of low-grade oligodendrogliomas to chemotherapy ${ }^{15,20,39,91}$ Furthermore, the combined loss of $1 \mathrm{p}$ and $19 \mathrm{q}$ predicts longer survival in patients with anaplastic oligodendroglioma, ${ }^{18,46,69,98,112}$ even after recurrence..$^{29}$

Currently, molecular genetic analyses can be used to divide anaplastic oligodendrogliomas into four therapeutically and prognostically relevant subgroups ${ }^{46}$ (Fig. 1). Briefly, anaplastic oligodendrogliomas displaying combined loss of $1 p$ and $19 q$ in the absence of additional defined genetic alterations respond to chemotherapy in a durable manner, thereby resulting in a mean patient survival of more than 10 years. Oligodendroglial lesions with loss of $1 p$ in the absence of $19 q$ loss, or tumors that have $1 \mathrm{p} / 19 \mathrm{q}$ loss in the presence of additional genetic alterations, also respond to chemotherapy, but their response is less durable and patient survival is shorter. In contrast, two additional molecular subgroups exist in the absence of $1 \mathrm{p}$ loss and are distin- guished based on the presence or absence of p53 mutation; these oligodendrogliomas respond to chemotherapy less frequently and are associated with a more aggressive clinical outcome. Thus, these data demonstrate how molecular genetic analyses could be used to aid treatment decisions from the time of diagnosis. For example, patients exhibiting $1 \mathrm{p} / 19 \mathrm{q}$ loss in the absence of other genetic alterations might forgo radiation therapy until recurrence, thereby avoiding the side effects attributed to brain irradiation in long-term survivors. In contrast, patients with tumors belonging to the fourth genetic subgroup, the one least likely to respond to chemotherapy, may choose radiation and/or a novel therapy as their primary treatment strategy. Moreover, loss of $1 \mathrm{p}$ has been demonstrated to be predictive of response to radiation. ${ }^{6}$

A number of additional genetic alterations have been correlated with prognosis in oligodendrogliomas. Mutation of p53 and loss of chromosome 10q have both been linked to poor prognosis, ${ }^{18,40,46,70,92,103,112}$ as has allelic loss of $9 \mathrm{p} 21$, or more specifically, deletion of the $C D K N 2 A$ gene. ${ }^{18,70}$ All of these genetic alterations have been shown to have a negative correlation with $1 \mathrm{p} / 19 \mathrm{q}$ loss in oligodendrogliomas. ${ }^{18,40,46,69,112}$

\section{Correlation of Molecular Genetics With Clinical Diagnostic Methods}

Correlation With Oligodendroglial Histological Features. As mentioned in the introductory section, one of the shortcomings of histology-based diagnoses is that the diagnosis of tumors with nonclassic histological features can be controversial. Using a high-throughput molecular genetics approach to address this issue, the power of a gene expression-based prediction model to aid the classification of high-grade gliomas was recently demonstrated..$^{75}$ In that study, supervised learning approaches were used to build a two-class model to separate a subset of anaplastic oligodendrogliomas and glioblastomas with "textbook" histological features. This two-class model was then used to predict a classification for a series of high-grade gliomas with nonclassic histological features. Because patients with anaplastic oligodendrogliomas experience a significantly longer average survival time than those with glioblastomas, ${ }^{54,77}$ survival was examined as an independent validation of the gene expression-based prediction model; classification based on expression profiling provided stronger outcome prediction than did classification based on standard pathological studies.

These data provided evidence that microarray-based classification may be better suited to distinguish between anaplastic oligodendrogliomas and glioblastomas in a clinically relevant manner. Subsequently, in an effort to develop an immunohistochemical panel capable of distinguishing between these two classes of tumors, a number of differentially expressed genes from the microarray study were confirmed at the protein level. One molecule, YKL-40, was highly expressed in glioblastomas compared with anaplastic oligodendrogliomas, and it was determined that immunohistochemical staining of YKL-40 alone could distinguish these tumors in a highly significant manner. ${ }^{74}$

In addition to correctly identifying oligodendrogliomas during the initial diagnosis, the therapeutic significance of subsequently testing these lesions for $1 \mathrm{p} / 19 \mathrm{q}$ loss was clear- 


\section{Classic Low Grade Oligodendroglioma Features}

- uniform and rounded nuclei, often with small nucleoli

- perinuclear halos

- even cellular distribution within tissue

- calcification and "chickenwire" vasculature (informative but not required)

\section{Low Grade Oligodendroglioma Astrocytic Features \\ - mildly pleomorphic, more hyperchromatic nuclei \\ - tapering eosinophilic cell processes \\ - irregular cellular distribution within tissue}

Fig. 2. Chart detailing histological features of classic low-grade oligodendrogliomas and low-grade oligodendrogliomas with astrocytic feature (see Sasaki, et al., 2002).

ly evident. In light of this fact, more neuropathologists began to perform $1 \mathrm{p} / 19 \mathrm{q}$ testing in their histologically diagnosed oligodendrogliomas. Interestingly, some of these practitioners began to recognize histological features that distinguished tumors with $1 \mathrm{p} / 19 \mathrm{q}$ loss from those with intact chromosomal 1p/19q. In one study, Burger, et al., ${ }^{12}$ reviewed 18 classic and borderline cases of infiltrating glioma. Of six cases diagnosed unanimously as oligodendroglial lesions, all had allelic loss of $1 \mathrm{p}$ and $19 \mathrm{q}$. Interestingly, none of these six tumors had TP53 mutations. In contrast, nine cases were assigned an astrocytic classification on review; all demonstrated intact $1 \mathrm{p}$ alleles and three exhibited TP53 mutations (TP53 status was not available in two of the nine cases). Notably, six of these nine tumors had been categorized as oligodendroglioma or mixed glioma by the referring institutions.

In a study by Ueki, et al., ${ }^{104}$ eight cases in a larger, nonselected series were diagnosed unanimously as oligodendrogliomas by four independent neuropathologists; one of these tumors had $19 \mathrm{q}$ loss but was noninformative for $1 \mathrm{p}$ status, and all of the remaining seven lesions demonstrated 1p/19q loss. In contrast, TP53 mutation was detected most often in tumors with astrocytic features. Furthermore, Sasaki, et al., ${ }^{91}$ selected a series of 44 low-grade oligodendrogliomas and divided the cases into two groups: classic oligodendroglioma and lesions with astrocytic features. The histological features used to classify tumors into each of these two groups are given in Fig. 2. Loss of 1p was observed in $86 \%$ of the classic oligodendrogliomas, whereas $73 \%$ of the oligodendroglial tumors with astrocytic features retained both allelic copies of $1 \mathrm{p}$. Thus, it appeared that glial tumors with $1 \mathrm{p} / 19 \mathrm{q}$ loss were the most likely to demonstrate an unequivocal oligodendroglial histology, regardless of tumor grade, whereas mutated p53 was associated with the presence of astrocytic histological features. Moreover, McDonald, et al. ${ }^{69}$ demonstrated that defining oligodendrogliomas with classic histological features in this manner yielded prognostic predictability similar to that provided by $1 \mathrm{p} / 19 \mathrm{q}$ loss.

The aforementioned studies give examples of how molecular genetics can aid histology-based classification of glial tumors. Nevertheless, because the current method of tumor specimen management in pathology departments worldwide makes use of formalin-fixed, paraffin-embedded tissues, immunohistochemistry is routinely used to aid diagnosis. Unfortunately, no immunohistochemical markers currently exist that exclusively stain oligodendrogliomas. As noted earlier, gene expression-based data have been used to develop a new immunohistochemical marker capable of labeling glioblastomas relative to anaplastic oligodendrogliomas. ${ }^{74,75}$ A number of laboratories are currently using this microarray-based approach in an attempt to identify oligodendroglioma-specific markers. With the ever-increasing numbers of gene expression-based and proteomic studies being performed, $32,42,47,51,73,75,116$ it is hoped that such clinically relevant oligodendroglial markers will be forthcoming in the future.

Correlation With Tumor Location and Pattern of Growth. Although initial molecular genetic studies in oligodendroglioma focused on correlations with clinical outcome, studies in which biological properties were investigated have begun to emerge. Zlatescu, et al., ${ }^{121}$ demonstrated that anaplastic oligodendrogliomas with allelic loss of $1 p$ and $19 q$ were significantly more likely to be situated in the frontal, parietal, and occipital lobes of the brain. In contrast, oligodendroglial tumors with intact $1 \mathrm{p}$ and $19 \mathrm{q}$ alleles, although histologically indistinguishable from lesions found in the frontal, parietal, and occipital lobes, arose more often in the temporal lobe, insula, and diencephalon. ${ }^{69,121}$ Similarly, most temporal oligoastrocytomas have also been found to have intact $1 \mathrm{p}$ and $19 \mathrm{q}$ alleles. ${ }^{72}$ In contrast to oligodendrogliomas, however, temporal oligoastrocytomas tended to exhibit more astrocytic histological features than those found in other areas of the brain and were often accompanied by p53 mutation. No association between molecular genetics and location has been established in astrocytic tumors. These findings raise the interesting question of whether different subtypes of oligodendroglial tumors might arise from different progenitor cells that are localized to specific regions of the brain or that appear at different stages of development. ${ }^{121}$

Beyond location of oligodendrogliomas, $1 \mathrm{p}$ and $19 \mathrm{q}$ status has also been linked to the pattern of growth of these lesions. Based on the clinical observation that oligodendrogliomas in deeper regions of the brain were more often well circumscribed on MR imaging and grew as expansive rather than infiltrative masses, Zlatescu, et al., ${ }^{121}$ investigated whether allelic loss of $1 p$ and $19 q$ correlated with the manner in which these oligodendrogliomas grew within the brain. In a series of 64 tumors, lesions in seven patients dis- 
played a bilateral rather than a unilateral pattern of growth; all of these oligodendrogliomas with bilateral growth demonstrated $1 \mathrm{p} / 19 \mathrm{q}$ loss. The possibility that oligodendrogliomas with $1 \mathrm{p} / 19 \mathrm{q}$ loss grow in a more infiltrative manner raises the additional hypothesis that this particular genetic alteration facilitates a distinct interplay with the extracellular environment. Clearly, because both the cell of origin for subtypes of oligodendrogliomas and the interaction that these lesions have with their environment could have profound implications for the clinical management of these tumors, additional investigations into the biological consequences of $1 \mathrm{p} / 19 \mathrm{q}$ loss are certainly warranted.

Correlation With Oligodendroglioma Imaging. Clinical management of malignant gliomas is highly dependent on MR imaging findings. Because of this, it is not surprising that the most recent advancements in the study of oligodendrogliomas have resulted from investigating possible correlations between $1 \mathrm{p} / 19 \mathrm{q}$ status and imaging characteristics. Again suggestive of a more infiltrative growth pattern for oligodendrogliomas with $1 \mathrm{p} / 19 \mathrm{q}$ loss, tumors with this genotype were more likely to demonstrate an indistinct border on $\mathrm{T}_{1}$-weighted MR images. In contrast, oligodendroglial lesions with intact chromosomal $1 p$ and $19 q$ tended to display sharper borders on MR imaging ${ }^{71}$ and sometimes displayed ring enhancement. ${ }^{18}$ Oligodendroglial tumors with $1 \mathrm{p} / 19 \mathrm{q}$ loss were also more likely to exhibit mixed signal intensity. Moreover, this signal heterogeneity, along with susceptibility change, correlated with the presence of intratumoral calcification in oligodendroglial tumors exhibiting 1p/19q loss, although the association between intratumoral calcification and susceptibility effects is likely to be indirect. Furthermore, tumors with $1 \mathrm{p} / 19 \mathrm{q}$ loss have also been associated with a hypermetabolic state, particularly in patients with low-grade oligodendrogliomas. ${ }^{16,111}$ Intriguingly, these data highlight the potential for methods of imaging-based molecular diagnostic modalities in the future.

\section{Role of Molecular Genetics in Clinical Management of Astrocytic Tumors}

Analogous to oligodendrogliomas, much is known about the molecular genetics of astrocytic tumors. ${ }^{44,53,63,76,79}$, 83,94 Glioblastomas, the most malignant astrocytic tumor, can generally be divided into two groups based on molecular analyses: those with TP53 mutation and those with EGFR amplification. ${ }^{54,65,110}$ Secondary glioblastomas, lesions that have arisen in a background of prior lower-grade astrocytoma, are often p53-mutated tumors, but p53 mutations can also be found in glioblastomas with no history of glioma. ${ }^{86,110,113}$ Tumors with EGFR amplification, however, are characteristic of primary, or de novo, glioblastomas. ${ }^{110,113}$ Glioblastomas with mutated p53 tend to occur in patients younger than those in whom the lesions are characterized by EGFR amplification, ${ }^{66,82}$ and young age at initial diagnosis is an important predictor of better outcome in these tumors.

A number of studies have been conducted to examine the independent prognostic implications of p53 mutation and EGFR overexpression or mutation, ${ }^{5,14,38,93,95,96,99}$ but much of this information implies that the relationship between age, p53 mutation, EGFR, and survival in astrocytic gliomas is rather complex. In one study, patients with glioblastoma were initially differentiated based on length of survival; nuclear expression of p53 was detected more frequently in long-term survivors, whereas overexpression of EGFR appeared to be slightly more common in short-term survivors. ${ }^{14}$ In comparison, when patients with glioblastoma were differentiated based on age, EGFR overexpression correlated with poor prognosis only in younger patients; older patients with overexpression of EGFR actually had a better prognosis. ${ }^{95,96,99}$ Moreover, among patients with glioblastoma who were younger than the median age, overexpression of EGFR was related to a shorter survival time in those with wild-type p53 but not in those whose tumors stained positively for p53 in an immunohistochemical study. ${ }^{96}$ In addition, EGFRvIII, a mutant form of EGFR, has been implicated as a predictor of unfavorable prognosis in patients surviving more than 1 year. ${ }^{38}$ The prognostic effects of p53 also appear to be dependent on the age of the patient. ${ }^{5}$

Another genetic alteration that has been associated with prognosis in astrocytic tumors is the allelic loss of chromosome $10 \mathrm{q}$. Loss of $10 \mathrm{q}$ is the most frequent genetic alteration in glioblastomas, ${ }^{45,49,77,81,108}$ and has been associated with a low survival rate. ${ }^{77,80,93,102}$ Furthermore, mutation of PTEN, a 10q gene, has also been correlated with poor prognosis. ${ }^{28,99}$ Additional molecular markers predicting a negative prognosis for patients with astrocytic gliomas have included the following: loss of chromosome $9 \mathrm{p}$ or $C D K N 2 \mathrm{~A}$ deletion, ${ }^{80}$ gains of $7 \mathrm{p}$ and $7 \mathrm{q},{ }^{57}$ activated phosphatidylinositol 3-kinase, ${ }^{21}$ YKL-40, ${ }^{78}$ and a dysfunctional RB pathway. ${ }^{2}$ Furthermore, $\mathrm{CGH}^{13,57,117}$ and gene expression profiling ${ }^{62,87}$ have also provided novel sources of prognostic information.

The predictive value of molecular genetics for determining treatment response has met with less success for astrocytic gliomas than for oligodendrogliomas. There has been some evidence for a correlation between EGFR overexpression and resistance to radiation, ${ }^{4,59-61}$ although much of this information has been obtained from in vitro studies. ${ }^{59-61}$ The YKL-40 molecule has also been implicated as a marker of radioresistance. ${ }^{78}$ Most recently, EGFR status has been investigated in astrocytic gliomas treated with erlotinib, a small-molecule inhibitor of EGFR. One study demonstrated that tumors with high levels of EGFR expression and low levels of phosphorylated PKB/Akt responded better to erlotinib than lesions with low levels of EGFR and high levels of phosphorylated PKB/Akt. ${ }^{36}$ Nevertheless, six of the 10 patients with $E G F R$ amplification did not respond to erlotinib, suggesting that this agent may be active only in a subset of gliomas with EGFR expression. ${ }^{19,36}$

\section{CONCLUSIONS}

Malignant gliomas are the most lethal of brain tumors. Much progress has been made in the treatment and prognosis of one subtype of glioma in particular, the anaplastic oligodendroglioma. In this paper I have attempted to highlight the role of molecular genetics in the improved clinical management of oligodendroglial tumors. Although much is also known about the molecular pathological characteristics of astrocytic gliomas, the significance of this information to the clinical management of these tumors has not been as striking as it has been for oligodendrogliomas. A number of reasons exist for this observation. First, patients 
with astrocytic tumors, particularly glioblastomas, have a much shorter survival time than individuals with oligodendroglial lesions; the median survival duration for patients with glioblastomas is less than 1 year, ${ }^{54}$ making it very difficult to stratify them to a degree meaningful enough for the development of prognostic markers. Similarly, the key reason for the success of $1 \mathrm{p}$ testing in patients with oligodendrogliomas was the marked response these tumors demonstrated to PCV chemotherapy; such highly effective treatments are not currently available for astrocytic tumors, hindering the development of response markers.

The recent emphasis on the development of targeted molecular therapies affords the possibility of more effective treatment options for nervous system tumors in the near future. This is made all the more exciting by the plethora of novel data coming out of studies in which methods such as array-based $\mathrm{CGH}$ and gene expression profiling are being used; these studies will greatly expand the number of potentially informative molecular markers. Therefore, it is hoped that the progress made in oligodendroglial tumors can serve as a model for improved clinical management through the use of molecular genetics, leaving the field of neurooncology poised to take advantage of these approaches when more effective treatments become available, not only for astrocytic gliomas but for nervous system tumors in general.

\section{Acknowledgments}

I thank Drs. J. Gregory Cairncross and David N. Louis. Greg and David sparked my initial interest in oligodendrogliomas and molecular genetics, respectively, allowing me to appreciate at an early stage the promise that the findings discussed in this paper brought to the field of neurooncology. I thank them for their continued guidance, support, and friendship.

\section{References}

1. Alonso ME, Bello MJ, Gonzalez-Gomez P, et al: Aberrant promoter methylation of multiple genes in oligodendrogliomas and ependymomas. Cancer Genet Cytogenet 144:134-142, 2003

2. Bäcklund LM, Nilsson BR, Goike HM, et al: Short postoperative survival for glioblastoma patients with a dysfunctional Rb1 pathway in combination with no wild-type PTEN. Clin Cancer Res 9:4151-4158, 2003

3. Barbashina V, Salazar P, Holland EC, et al: Allelic losses at $1 \mathrm{p} 36$ and 19q13 in gliomas: correlation with histologic classification, definition of a 150-kb minimal deleted region on $1 \mathrm{p} 36$, and evaluation of CAMTAI as a candidate tumor suppressor gene. Clin Cancer Res 11:1119-1128, 2005

4. Barker FG II, Simmons ML, Chang SM, et al: EGFR overexpression and radiation response in glioblastoma multiforme. Int J Radiat Oncol Biol Phys 51:410-418, 2001

5. Batchelor TT, Betensky RA, Esposito JM, et al: Age-dependent prognostic effects of genetic alterations in glioblastoma. Clin Cancer Res 10:228-233, 2004

6. Bauman GS, Ino Y, Ueki K, et al: Allelic loss of chromosome $1 \mathrm{p}$ and radiotherapy plus chemotherapy in patients with oligodendrogliomas. Int J Radiat Oncol Biol Phys 48:825-830, 2000

7. Bello MJ, Leone PE, Vaquero J, et al: Allelic loss at $1 p$ and $19 q$ frequently occurs in association and may represent early oncogenic events in oligodendroglial tumors. Int J Cancer 64: 207-210, 1995

8. Bello MJ, Vaquero J, de Campos JM, et al: Molecular analysis of chromosome 1 abnormalities in human gliomas reveals frequent loss of 1p in oligodendroglial tumors. Int J Cancer 57: 172-175, 1994
9. Bigner SH, Matthews MR, Rasheed BKA, et al: Molecular genetic aspects of oligodendrogliomas including analysis by comparative genomic hybridization. Am J Pathol 155:375-386, 1999

10. Bortolotto S, Chiado-Piat L, Cavalla P, et al: $C D K N 2 A / \mathrm{p} 16$ inactivation in the prognosis of oligodendrogliomas. Int $\mathbf{J}$ Cancer 88:554-557, 2000

11. Bredel M, Bredel C, Juric D, et al: High-resolution genome-wide mapping of genetic alterations in human glial brain tumors. Cancer Res 65:4088-4096, 2005

12. Burger PC, Minn AY, Smith JS, et al: Losses of chromosomal arms $1 \mathrm{p}$ and $19 \mathrm{q}$ in the diagnosis of oligodendroglioma. A study of paraffin-embedded sections. Mod Pathol 14:842-853, 2001

13. Burton EC, Lamborn KR, Feuerstein BG, et al: Genetic aberrations defined by comparative genomic hybridization distinguish long-term from typical survivors of glioblastoma. Cancer Res 62:6205-6210, 2002

14. Burton EC, Lamborn KR, Forsyth P, et al: Aberrant p53, mdm2, and proliferation differ in glioblastomas from long-term compared with typical survivors. Clin Cancer Res 8:180-187, 2002

15. Byrne TN: Response of low-grade oligodendroglial tumors to temozolomide. J Neurooncol 70:279-280, 2004

16. Cairncross JG: Imaging molecular signatures in oligodendroglioma. Clin Cancer Res 10:7109-7111, 2004

17. Cairncross JG, Macdonald DR: Successful chemotherapy for recurrent malignant oligodendroglioma. Ann Neurol 23:360-364, 1988

18. Cairncross JG, Ueki K, Zlatescu MC, et al: Specific genetic predictors of chemotherapeutic response and survival in patients with anaplastic oligodendrogliomas. J Natl Cancer Inst 90: 1473-1479, 1998

19. Cappuzzo F: Erlotinib in gliomas: should selection be based on EGFR and Akt analyses? J Natl Cancer Inst 97:868-869, 2005

20. Chahlavi A, Kanner A, Peereboom D, et al: Impact of chromosome $1 p$ status in response of oligodendroglioma to temozolomide: preliminary results. J Neurooncol 61:267-273, 2003

21. Chakravarti A, Zhai G, Suzuki Y, et al: The prognostic significance of phosphatidylinositol 3-kinase pathway activation in human gliomas. J Clin Oncol 22:1926-1933, 2004

22. Chinot OL, Honore S, Dufour H, et al: Safety and efficacy of temozolomide in patients with recurrent anaplastic oligodendrogliomas after standard radiotherapy and chemotherapy. J Clin Oncol 19:2449-2455, 2001

23. Coons SW, Johnson PC, Scheithauer BW, et al: Improving diagnostic accuracy and interobserver concordance in the classification and grading of primary gliomas. Cancer 79:1381-1393, 1997

24. Cowell JK, Barnett GH, Nowak NJ: Characterization of the $1 \mathrm{p} / 19 \mathrm{q}$ chromosomal loss in oligodendrogliomas using comparative genomic hybridization arrays (CGHa). J Neuropathol Exp Neurol 63:151-158, 2004

25. Dong S, Pang JCS, Hu J, et al: Transcriptional inactivation of TP73 expression in oligodendroglial tumors. Int J Cancer 98: 370-375, 2002

26. Dong SM, Pang JCS, Poon WS, et al: Concurrent hypermethylation of multiple genes is associated with grade of oligodendroglial tumors. J Neuropathol Exp Neurol 60:808-816, 2001

27. Dong Z, Pang JCS, Ng MH, et al: Identification of two contiguous minimally deleted regions on chromosome 1p36.31-p36.32 in oligodendroglial tumors. Br J Cancer 91:1105-1111, 2004

28. Ermoian RP, Furniss CS, Lamborn KR, et al: Dysregulation of PTEN and protein kinase B is associated with glioma histology and patient survival. Clin Cancer Res 8:1100-1106, 2002

29. Fallon KB, Palmer CA, Roth KA, et al: Prognostic value of 1p, 19q, 9p, 10q, and EGFR-FISH analyses in recurrent oligodendrogliomas. J Neuropathol Exp Neurol 63:314-322, 2004

30. Felsberg J, Erkwoh A, Sabel MC, et al: Oligodendroglial tumors: refinement of candidate regions on chromosome arm $1 \mathrm{p}$ and correlation of $1 \mathrm{p} / 19 \mathrm{q}$ status with survival. Brain Pathol 14:121-130, 2004 
31. Fuller GN, Bigner SH: Amplified cellular oncogenes in neoplasms of the human central nervous system. Mutat Res 276: 299-306, 1992

32. Fuller GN, Hess KR, Rhee $\mathrm{CH}$, et al: Molecular classification of human diffuse gliomas by multidimensional scaling analysis of gene expression profiles parallels morphology-based classification, correlates with survival, and reveals clinically-relevant novel glioma subsets. Brain Pathol 12:108-116, 2002

33. Giannini C, Scheithauer BW, Weaver AL, et al: Oligodendrogliomas: reproducibility and prognostic value of histologic diagnosis and grading. J Neuropathol Exp Neurol 60:248-262, 2001

34. Glantz MJ, Burger PC, Herndon JE II, et al: Influence of the type of surgery on the histologic diagnosis in patients with anaplastic gliomas. Neurology 41:1741-1744, 1991

35. Glass J, Hochberg FH, Gruber ML, et al: The treatment of oligodendrogliomas and mixed oligodendroglioma-astrocytomas with PCV chemotherapy. J Neurosurg 76:741-745, 1992

36. Haas-Kogan DA, Prados MD, Tihan T, et al: Epidermal growth factor receptor, protein kinase B/Akt, and glioma response to erlotinib. J Natl Cancer Inst 97:880-887, 2005

37. Hartmann C, Johnk L, Kitange G, et al: Transcript map of the 3.7-mb D19S112-d19S246 candidate tumor suppressor region on the long arm of chromosome 19. Cancer Res 62:4100-4108, 2002

38. Heimberger AB, Hlatky R, Suki D, et al: Prognostic effect of epidermal growth factor receptor and EGFRvIII in glioblastoma multiforme patients. Clin Cancer Res 11:1462-1466, 2005

39. Hoang-Xuan K, Capelle L, Kujas M, et al: Temozolomide as initial treatment for adults with low-grade oligodendrogliomas or oligoastrocytomas and correlation with chromosome $1 \mathrm{p}$ deletions. J Clin Oncol 22:3133-3138, 2004

40. Hoang-Xuan K, He J, Huguet S, et al: Molecular heterogeneity of oligodendrogliomas suggests alternative pathways in tumor progression. Neurology 57:1278-1281, 2001

41. Hong C, Maunakea A, Jun P, et al: Shared epigenetic mechanisms in human and mouse gliomas inactivate expression of the growth suppressor SLC5A8. Cancer Res 65:3617-3623, 2005

42. Huang H, Okamoto Y, Yokoo H, et al: Gene expression profiling and subgroup identification of oligodendrogliomas. Oncogene 23:6012-6022, 2004

43. Husemann K, Wolter M, Buschges R, et al: Identification of two distinct deleted regions on the short arm of chromosome 1 and rare mutation of the CDKN2C gene from 1p32 in oligodendroglial tumors. J Neuropathol Exp Neurol 58:1041-1050, 1999 (Erratum in J Neuropathol Exp Neurol 59:88, 2000)

44. Ichimura K, Ohgaki H, Kleihues P, et al: Molecular pathogenesis of astrocytic tumors. J Neurooncol 70:137-160, 2004

45. Ichimura K, Schmidt EE, Miyakawa A, et al: Distinct patterns of deletion on 10p and 10q suggest involvement of multiple tumor suppressor genes in the development of astrocytic gliomas of different malignancy grades. Genes Chromosomes Cancer 22:9-15, 1998

46. Ino Y, Betensky RA, Zlatescu MC, et al: Molecular subtypes of anaplastic oligodendroglioma: implications for patient management at diagnosis. Clin Cancer Res 7:839-845, 2001

47. Iwadate Y, Sakaida T, Hiwasa T, et al: Molecular classification and survival prediction in human gliomas based on proteome analysis. Cancer Res 64:2496-2501, 2004

48. Jeuken JW, Sprenger SH, Wesseling P, et al: Identification of subgroups of high-grade oligodendroglial tumors by comparative genomic hybridization. J Neuropathol Exp Neurol 58: 606-612, 1999

49. Karlbom AE, James CD, Boethius J, et al: Loss of heterozygosity in malignant gliomas involves at least three distinct regions on chromosome 10. Hum Genet 92:169-174, 1993

50. Kim L, Hochberg FH, Thornton AF, et al: Procarbazine, lomustine, and vincristine (PCV) chemotherapy for grade III and grade IV oligoastrocytomas. J Neurosurg 85:602-607, 1996
51. Kim S, Dougherty ER, Shmulevich I, et al: Identification of combination gene sets for glioma classification. Mol Cancer Ther 1:1229-1236, 2002

52. Kitange G, Misra A, Law M, et al: Chromosomal imbalances detected by array comparative genomic hybridization in human oligodendrogliomas and mixed oligoastrocytomas. Genes Chromosomes Cancer 42:68-77, 2005

53. Kitange GJ, Templeton KL, Jenkins RB: Recent advances in the molecular genetics of primary gliomas. Curr Opin Oncol 15: 197-203, 2003

54. Kleihues P, Cavenee WK (eds): Pathology and Genetics of Tumours of the Nervous System. Lyon: IARC, 2000

55. Kraus JA, Koopmann J, Kaskel P, et al: Shared allelic losses on chromosomes $1 p$ and $19 q$ suggest a common origin of oligodendroglioma and oligoastrocytoma. J Neuropathol Exp Neurol 54:91-95, 1995

56. Kros JM, van Run PR, Alers JC, et al: Genetic aberrations in oligodendroglial tumors: an analysis using comparative genomic hybridization (CGH). J Pathol 188:282-288, 1999

57. Kunwar S, Mohapatra G, Bollen A, et al: Genetic subgroups of anaplastic astrocytoma correlate with patient age and survival. Cancer Res 61:7683-7688, 2001

58. Kyritsis AP, Yung WK, Bruner J, et al: The treatment of anaplastic oligodendrogliomas and mixed gliomas. Neurosurgery 32:365-371, 1993

59. Lammering G, Hewit TH, Holmes M, et al: Inhibition of the type III epidermal growth factor receptor variant mutant receptor by dominant-negative EGFR-CD533 enhances malignant glioma cell radiosensitivity. Clin Cancer Res 10:6732-6743, 2004

60. Lammering G, Valerie K, Lin PS, et al: Radiosensitization of malignant glioma cells through overexpression of dominantnegative epidermal growth factor receptor. Clin Cancer Res 7: 682-690, 2001

61. Li B, Yuan M, Kim IA, et al: Mutant epidermal growth factor receptor displays increased signaling through the phosphatidylinositol-3 kinase/AKT pathway and promotes radioresistance in cells of astrocytic origin. Oncogene 23:4594-4602, 2004

62. Liang Y, Diehn M, Watson N, et al: Gene expression profiling reveals molecularly and clinically distinct subtypes of glioblastoma multiforme. Proc Natl Acad Sci U S A 102:5814-5819, 2005

63. Louis DN, Cavenee WK: Molecular biology of central nervous system neoplasms, in DeVita VT Jr, Hellman S, Rosenberg SA (eds): Cancer: Principles and Practice of Oncology, ed 7. Philadelphia: Lippincott Williams \& Wilkins, 2005, pp 1827-1833

64. Louis DN, Holland EC, Cairncross JG: Glioma classification: a molecular reappraisal. Am J Pathol 159:779-786, 2001

65. Louis DN, Pomeroy SL, Cairncross JG: Focus on central nervous system neoplasia. Cancer Cell 1:125-128, 2002

66. Louis DN, von Deimling A, Chung RY, et al: Comparative study of 553 gene and protein alterations in human astrocytomic tumors. J Neuropathol Exp Neurol 52:31-38, 1993

67. Macdonald DR, Gaspar LE, Cairncross JG: Successful chemotherapy for newly diagnosed aggressive oligodendroglioma. Ann Neurol 27:573-574, 1990

68. Mason WP, Krol GS, DeAngelis LM: Low-grade oligodendroglioma responds to chemotherapy. Neurology 46:203-207, 1996

69. McDonald JM, See SJ, Tremont IW, et al: The prognostic impact of histology and $1 \mathrm{p} / 19 \mathrm{q}$ status in anaplastic oligodendroglial tumors. Cancer 104:1468-1477, 2005

70. McLendon RE, Herndon JE II, West B, et al: Survival analysis of presumptive prognostic markers among oligodendrogliomas. Cancer 104:1693-1699, 2005

71. Megyesi JF, Kachur E, Lee DH, et al: Imaging correlates of molecular signatures in oligodendrogliomas. Clin Cancer Res 10:4303-4306, 2004

72. Mueller W, Hartmann C, Hoffmann A, et al: Genetic signature 
of oligoastrocytomas correlates with tumor location and denotes distinct molecular subsets. Am J Pathol 161:313-319, 2002

73. Mukasa A, Ueki K, Matsumoto S, et al: Distinction in gene expression profiles of oligodendrogliomas with and without allelic loss of 1p. Oncogene 21:3961-3968, 2002

74. Nutt CL, Betensky RA, Brower MA, et al: YKL-40 is a differential diagnostic marker for histologic subtypes of high-grade gliomas. Clin Cancer Res 11:2258-2264, 2005

75. Nutt CL, Mani DR, Betensky RA, et al: Gene expression-based classification of malignant gliomas correlates better with survival than histological classification. Cancer Res 63:1602-1607, 2003

76. Ohgaki H: Genetic pathways to glioblastomas. Neuropathology 25:1-7, 2005

77. Ohgaki H, Kleihues P: Population-based studies on incidence, survival rates, and genetic alterations in astrocytic and oligodendroglial gliomas. J Neuropathol Exp Neurol 64:479-489, 2005

78. Pelloski CE, Mahajan A, Maor M, et al: YKL-40 expression is associated with poorer response to radiation and shorter overall survival in glioblastoma. Clin Cancer Res 11:3326-3334, 2005

79. Rao RD, James CD: Altered molecular pathways in gliomas: an overview of clinically relevant issues. Semin Oncol 31:595-604, 2004

80. Rasheed A, Herndon JE, Stenzel TT, et al: Molecular markers of prognosis in astrocytic tumors. Cancer 94:2688-2697, 2002

81. Rasheed BK, McLendon RE, Friedman HS, et al: Chromosome 10 deletion mapping in human gliomas: a common deletion region in 10q25. Oncogene 10:2243-2246, 1995

82. Rasheed BK, McLendon RE, Herndon JE, et al: Alterations of the TP53 gene in human gliomas. Cancer Res 54:1324-1330, 1994

83. Reifenberger G, Collins VP: Pathology and molecular genetics of astrocytic gliomas. J Mol Med 82:656-670, 2004

84. Reifenberger J, Reifenberger G, Ichimura K, et al: Epidermal growth factor receptor expression in oligodendroglial tumors. Am J Pathol 149:29-35, 1996

85. Reifenberger J, Reifenberger G, Liu L, et al: Molecular genetic analysis of oligodendroglial tumors shows preferential allelic deletions on 19q and 1p. Am J Pathol 145:1175-1190, 1994

86. Reifenberger J, Ring GU, Gies U, et al: Analysis of p53 mutation and epidermal growth factor receptor amplification in recurrent gliomas with malignant progression. J Neuropathol Exp Neurol 55:822-831, 1996

87. Rich JN, Hans C, Jones B, et al: Gene expression profiling and genetic markers in glioblastoma survival. Cancer Res 65: 4051-4058, 2005

88. Roerig P, Nessling M, Radlwimmer B, et al: Molecular classification of human gliomas using matrix-based comparative genomic hybridization. Int J Cancer 117:95-103, 2005

89. Rossi MR, Gaile D, Laduca J, et al: Identification of consistent novel submegabase deletions in low-grade oligodendrogliomas using array-based comparative genomic hybridization. Genes Chromosomes Cancer 44:85-96, 2005

90. Rubio MP, Correa KM, Ueki K, et al: The putative glioma tumor suppressor gene on chromosome 19q maps between APOC2 and HRC. Cancer Res 54:4760-4763, 1994

91. Sasaki H, Zlatescu MC, Betensky RA, et al: Histopathologicalmolecular genetic correlations in referral pathologist-diagnosed low-grade "oligodendroglioma." J Neuropathol Exp Neurol 61:58-63, 2002

92. Sasaki H, Zlatescu MC, Betensky RA, et al: PTEN is a target of chromosome 10q loss in anaplastic oligodendrogliomas and PTEN alterations are associated with poor prognosis. Am J Pathol 159:359-367, 2001

93. Schmidt MC, Antweiler S, Urban N, et al: Impact of genotype and morphology on the prognosis of glioblastoma. J Neuropathol Exp Neurol 61:321-328, 2002
94. Sehgal A: Molecular changes during the genesis of human gliomas. Semin Surg Oncol 14:3-12, 1998

95. Shinojima N, Tada K, Shiraishi S, et al: Prognostic value of epidermal growth factor receptor in patients with glioblastoma multiforme. Cancer Res 63:6962-6970, 2003

96. Simmons ML, Lamborn KR, Takahashi M, et al: Analysis of complex relationships between age, p53, epidermal growth factor receptor, and survival in glioblastoma patients. Cancer Res 61:1122-1128, 2001

97. Smith JS, Alderete B, Minn Y, et al: Localization of common deletion regions on $1 \mathrm{p}$ and $19 \mathrm{q}$ in human gliomas and their association with histological subtype. Oncogene 18:4144-4152, 1999

98. Smith JS, Perry A, Borell TJ, et al: Alterations of chromosome arms $1 p$ and $19 q$ as predictors of survival in oligodendrogliomas, astrocytomas, and mixed oligoastrocytomas. J Clin Oncol 18:636-645, 2000

99. Smith JS, Tachibana I, Passe SM, et al: PTEN mutation, EGFR amplification, and outcome in patients with anaplastic astrocytoma and glioblastoma multiforme. J Natl Cancer Inst 93: 1246-1256, 2001

100. Smith JS, Tachibana I, Pohl U, et al: A transcript map of the chromosome $19 q$-arm glioma tumor suppressor region. Genomics 64:44-50, 2000

101. Smith JS, Wang XY, Qian J, et al: Amplification of the platelet-derived growth factor receptor-A (PDGFRA) gene occurs in oligodendrogliomas with grade IV anaplastic features. J Neuropathol Exp Neurol 59:495-503, 2000

102. Tada K, Shiraishi S, Kamiryo T, et al: Analysis of loss of heterozygosity on chromosome 10 in patients with malignant astrocytic tumors: correlation with patient age and survival. J Neurosurg 95:651-659, 2001

103. Thiessen B, Maguire JA, McNeil K, et al: Loss of heterozygosity for loci on chromosome arms $1 \mathrm{p}$ and $10 \mathrm{q}$ in oligodendroglial tumors: relationship to outcome and chemosensitivity. J Neurooncol 64:271-278, 2003

104. Ueki K, Nishikawa R, Nakazato Y, et al: Correlation of histology and molecular genetic analysis of $1 \mathrm{p}, 19 \mathrm{q}, 10 \mathrm{q}$, TP53, $E G F R, C D K 4$, and $C D K N 2 A$ in 91 astrocytic and oligodendroglial tumors. Clin Cancer Res 8:196-201, 2002

105. Uhlmann K, Rohde K, Zeller C, et al: Distinct methylation profiles of glioma subtypes. Int J Cancer 106:52-59, 2003

106. van den Bent MJ, Keime-Guibert F, Brandes AA, et al: Temozolomide chemotherapy in recurrent oligodendroglioma. Neurology 57:340-342, 2001

107. van den Bent MJ, Taphoorn MJB, Brandes AA, et al: Phase II study of first-line chemotherapy with temozolomide in recurrent oligodendroglial tumors: the European Organization for Research and Treatment of Cancer Brain Tumor Group Study 26971. J Clin Oncol 21:2525-2528, 2003

108. von Deimling A, Louis DN, von Ammon K, et al: Association of epidermal growth factor receptor gene amplification with loss of chromosome 10 in human glioblastoma multiforme. J Neurosurg 77:295-301, 1992

109. von Deimling A, Louis DN, von Ammon K, et al: Evidence for a tumor suppressor gene on chromosome 19q associated with human astrocytomas, oligodendrogliomas, and mixed gliomas. Cancer Res 52:4277-4279, 1992

110. von Deimling A, von Ammon K, Schoenfeld D, et al: Subsets of glioblastoma multiforme defined by molecular genetic analysis. Brain Pathol 3:19-26, 1993

111. Walker C, du Plessis DG, Fildes D, et al: Correlation of molecular genetics with molecular and morphological imaging in gliomas with an oligodendroglial component. Clin Cancer Res 10:7182-7191, 2004

112. Walker C, du Plessis DG, Joyce KA, et al: Molecular pathology and clinical characteristics of oligodendroglial neoplasms. Ann Neurol 57:855-865, 2005

113. Watanabe K, Tachibana O, Sata K, et al: Overexpression of 


\section{Molecular genetics of oligodendrogliomas}

the EGF receptor and p53 mutations are mutually exclusive in the evolution of primary and secondary glioblastomas. Brain Pathol 6:217-224, 1996

114. Watanabe T, Nakamura M, Yonekawa Y, et al: Promoter hypermethylation and homozygous deletion of the p14ARF and p16INK4a genes in oligodendrogliomas. Acta Neuropathol 101:185-189, 2001

115. Watanabe T, Yokoo H, Yokoo M, et al: Concurrent inactivation of RB1 and TP53 pathways in anaplastic oligodendrogliomas. J Neuropathol Exp Neurol 60:1181-1189, 2001

116. Watson MA, Perry A, Budhjara V, et al: Gene expression profiling with oligonucleotide microarrays distinguishes World Health Organization grade of oligodendrogliomas. Cancer Res 61:1825-1829, 2001

117. Wiltshire RN, Herndon JE II, Lloyd A, et al: Comparative genomic hybridization analysis of astrocytomas: prognostic and diagnostic implications. J Mol Diagn 6:166-179, 2004

118. Wolter M, Reifenberger J, Blaschke B, et al: Oligodendroglial tumors frequently demonstrate hypermethylation of the CDKN2A (MTS1, p16INK4a), p14ARF, and CDKN2B (MTS2, p15INK4b) tumor suppressor genes. J Neuropathol Exp Neurol 60:1170-1180, 2001
119. Yang P, Kollmeyer TM, Buckner K, et al: Polymorphisms in GLTSCR1 and ERCC2 are associated with the development of oligodendrogliomas. Cancer 103:2363-2372, 2005

120. Yong WH, Chou D, Ueki K, et al: Chromosome 19q deletions in human gliomas overlap telomeric to D19S219 and may target a $425 \mathrm{~kb}$ region centromeric to D19S112. J Neuropathol Exp Neurol 54:622-626, 1995

121. Zlatescu MC, TehraniYazdi A, Sasaki H, et al: Tumor location and growth pattern correlate with genetic signature in oligodendroglial neoplasms. Cancer Res 61:6713-6715, 2001

Manuscript received September 26, 2005.

Accepted in final form October 20, 2005.

This study was funded by The Oligo Brain Tumor Fund of The National Brain Tumor Foundation and The James S. McDonnell Foundation.

Address reprint requests to: Catherine L. Nutt, Ph.D., Molecular Pathology Unit, CNY 6005, Massachusetts General Hospital, 149 13th Street, Charlestown, Massachusetts 02129. email: cnutt@partners.org. 